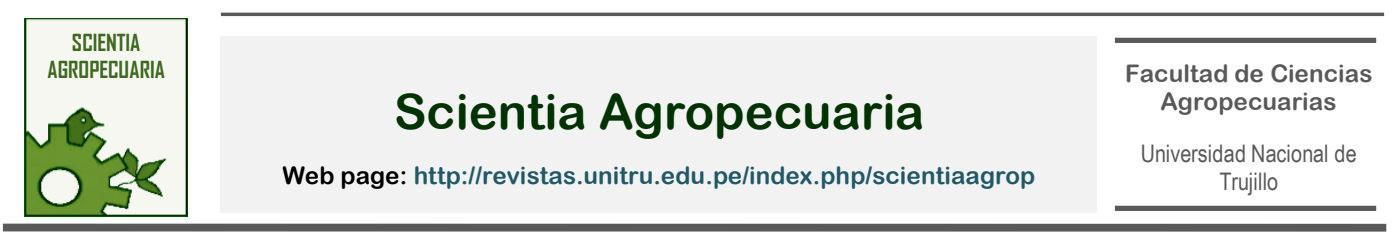

\title{
REVIEW
}

\section{Bacteriophage cocktail as a substitute for antibiotic-type growth promoters in poultry}

Coctel de bacteriófagos como sustituto de promotores de crecimiento tipo antibiótico en avicultura

C. E. Honorio-Javes ${ }^{1 *}$ (D) $;$ Y. Vallenas-Sánchez² $\mathbb{D}^{\mathbb{D}} ;$ J. T. Bazán Pérez ${ }^{3}$ (D)

1 Facultad de Ciencias Agropecuarias de la Universidad Nacional de Trujillo, Perú. Av. Juan Pablo II s/n.

2 Facultad de ciencias agrarias de la Universidad Privada Antenor Orrego. Trujillo, Perú. Av. América Sur 3145, urb. Monserrate.

3 Alumna de IX ciclo, Facultad de Ciencias Agropecuarias de la Universidad Nacional de Trujillo, Perú. Av. Juan Pablo II s/n.

*Corresponding author: cehonorioj@unitru.edu.pe (C. E. Honorio-Javes).

Received: 16 November 2020. Accepted: 8 August 2021. Published: 8 October 2021.

\begin{abstract}
Aviculture is forced to find alternatives to replace antibiotic-type growth promoters to reduce antimicrobial resistance. Among these alternatives we have bacteriophages that are the natural predators of bacteria; however, research point out to their use as therapeutics and not as growth promoters. For this reason, this review article focuses on discussing and projecting the use of lithic bacteriophage cocktails as growth promoters in commercial breeding of broilers, laying hens and quails. Evaluating its effects on production parameters, its application in drinking water and food, phage protection strategies on gastrointestinal pH changes and high pelleting temperatures, strategies against phage-resistance, its effects on the intestinal microbiota, and the use of autophages versus commercial products. It is concluded that the optimal use of bacteriophages in aviculture is through mixed cocktails of protected lithic autophages. Finally, it is recommended to compare the use of mixed lithic autophage cocktails with mixed commercial phage cocktails that exist on the market; Additionally, the combination of mixed cocktails of protected lithic autophages with other alternatives such as probiotics, prebiotics, essential oils and organic acids should be evaluated, and this combination should be compared with the use of growth-promoting antibiotics.
\end{abstract}

Keywords: gut microbiota; antimicrobial resistance; phage resistance; phage therapy; Salmonella spp.; E. coli.

\section{Resumen}

La industria avícola se ve en la obligación de encontrar alternativas que sustituyan a los promotores de crecimiento de tipo antibiótico para reducir la resistencia antimicrobiana. Entre dichas alternativas tenemos a los bacteriófagos que son los depredadores naturales de las bacterias; sin embargo, las investigaciones realizadas apuntan a su utilización como terapéuticos y no como promotores de crecimiento. Por tal motivo, el presente artículo de revisión se enfoca en discutir y proyectar el empleo de cocteles de bacteriófagos líticos como promotores de crecimiento en crianzas comerciales de pollos de engorde, gallinas de postura y codornices. Evaluando sus efectos sobre los parámetros productivos, su aplicación en agua de bebida y alimento, las estrategias de protección de fagos sobre los cambios de pH gastrointestinal y las altas temperaturas de peletización, estrategias contra la fago-resistencia, sus efectos sobre la microbiota intestinal, y el uso de autofagos versus los productos comerciales. Se concluye que la utilización óptima de bacteriófagos en avicultura comercial es mediante cocteles mixtos de autofagos líticos protegidos. Finalmente, se recomienda comparar el uso de cocteles mixtos de autofagos líticos con cocteles mixtos de fagos comerciales que existen en el mercado; adicionalmente, se debe evaluar la combinación de cocteles mixtos de autofagos líticos protegidos con otras alternativas como probióticos, prebióticos, aceites esenciales y ácidos orgánicos y comparar dicha combinación con el uso de antibióticos promotores de crecimiento.

Palabras clave: microbiota intestinal; resistencia antimicrobiana; fago-resistencia; terapia de fagos; Salmonella spp.; E. coli.

DOI: https://dx.doi.org/10.17268/sci.agropecu.2021.054

Cite this article:

Honorio-Javes, C. E., Vallenas-Sánchez, Y., \& Bazán, J, T. (2021). Coctel de bacteriófagos como sustituto de promotores de crecimiento tipo antibiótico en avicultura. Scientia Agropecuaria, 12(4), 499-508. 


\section{Introducción}

En los últimos años, ha aumentado el interés en los bacteriófagos o fagos, puesto que las nuevas variables a tener en cuenta son: La resistencia bacteriana a los antimicrobianos encontrada tanto en animales como en humanos (Ngamwongsatit et al., 2016; Zwe et al., 2018; ParryHanson et al., 2020; Assafi et al., 2020), la transferencia de dichos genes de resistencia en el medio ambiente a través de las aguas residuales de los centros de producción (Hubbard et al., 2020; Mazhar et al., 2020; Amato et al., 2020) y la prohibición del uso de antibióticos como promotores de crecimiento en algunos países (ESVAC, 2017). En la última década, se han publicado varios artículos de investigación experimental sobre el empleo de fagos como sustitutos de antibióticos en la industria avícola (Fig. 1a). Sin embargo, dichos trabajos están dirigidos a su aplicación terapéutica mas no a su utilización como promotor de crecimiento; del mismo modo, pocos trabajos utilizaron la dosificación en masa mediante el alimento o el agua, en su lugar, se enfocan en la dosificación individualizada mediante sondas y otras herramientas (Fig. 1b).

El presente trabajo revisa el uso de cocteles de bacteriófagos líticos como promotores de crecimiento y sus efectos sobre los parámetros productivos, estrategias de protección contra los cambios de $\mathrm{pH}$ y las altas temperaturas, las vías de administración para su aplicación en masa en crianza comercial y su comparación con los promotores de crecimiento de tipo antibiótico.

\section{2. ¿Qué son los bacteriófagos?}

Los bacteriófagos o fagos son los depredadores naturales de las bacterias, estos virus actúan como parásitos intracelulares de las mismas y tienen alta especificidad, por lo cual no afectan a los microorganismos benéficos (Gebru et al., 2010). Además, estos virus se encuentran en grandes cantidades en la naturaleza (Welsh et al., 2020).
Los fagos tienen distintos ciclos de infección dentro del hospedero bacteriano: infección lítica, lisogénica, pseudolisogénica y crónica (Weinbauer, 2004). Según el ciclo de infección se pueden clasificar en fagos virulentos o líticos y fagos lisogénicos o templados. Los fagos líticos no permiten la multiplicación bacteriana, no obstante, los templados sí la permiten cuando la población de estas es baja. De hecho, los fagos templados juegan un papel importante al transmitir genes de resistencia antimicrobiana (Colomer-Lluch, 2011; Wipf et al., 2014). Los estudios actuales de la fago-terapia se orientan al uso de fagos líticos, pertenecientes a los Caudovirales que comprenden a las familias Myoviridae, Siphoviridae y Podoviridae (Ackerman, 2011).

La infección de los fagos líticos inicia con el reconocimiento de receptores específicos en la membrana bacteriana y la consecuente adsorción del virus, luego, el fago introduce su material genético (ADN o ARN) en la bacteria y posteriormente se replica dentro de ella. Finalmente, liberan holinas y endolisinas para formar poros en la membrana, causando despolarización que produce lisis bacteriana y con ello liberación de nuevos fagos (Figura 2). Por lo tanto, se justifica el uso exclusivo de fagos líticos en avicultura comercial.

\section{Bacteriófagos usados contra bacterias que atacan a las aves}

Los fagos fueron obtenidos tanto de aguas residuales, heces y tejidos, los cuales fueron desafiados con algunas de las principales bacterias patógenas que aquejan a la avicultura como las causantes de colibacilosis, tifosis y pullorosis aviar demostrando ser eficaces en reducir la mortalidad de las aves y la población de las bacterias patógenas; la mayor dosis empleada fue de 2,5×109 UFP/animal y se suministraron en medio sólido y líquido (Tabla 1).

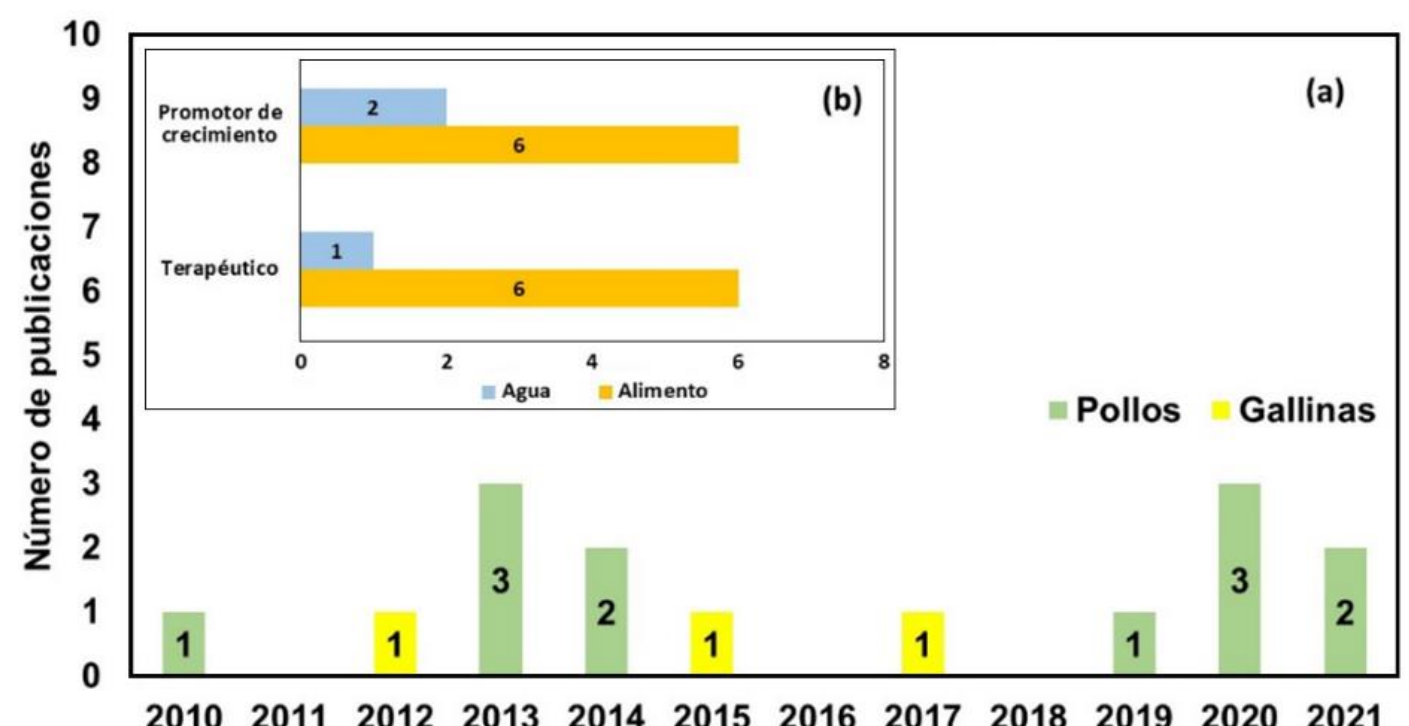

Figura 1. a Investigaciones experimentales de bacteriófagos usados como terapéuticos y promotores de crecimiento en avicultura mediante el alimento o agua según especie avícola. b Investigaciones experimentales de bacteriófagos usados como terapéuticos y promotores de crecimiento en avicultura suministrados mediante el agua y el alimento. Información obtenida de la base de datos de Scopus (Criterio de búsqueda: Título de artículo, resumen y palabras clave: "poultry", "phages" en el periodo 2010-2021). 

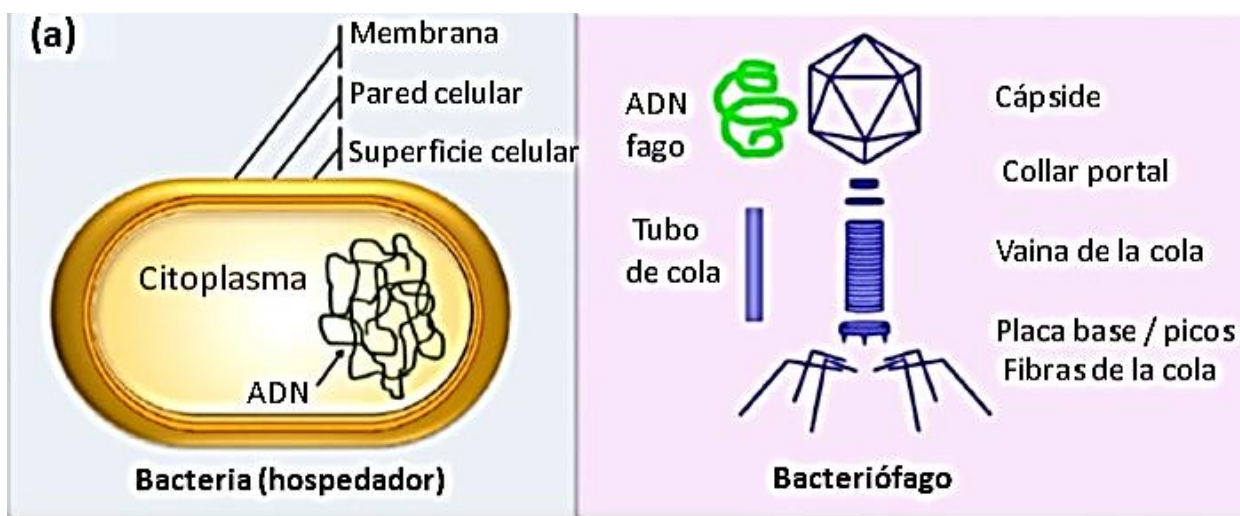

(b)

Bacteriófago
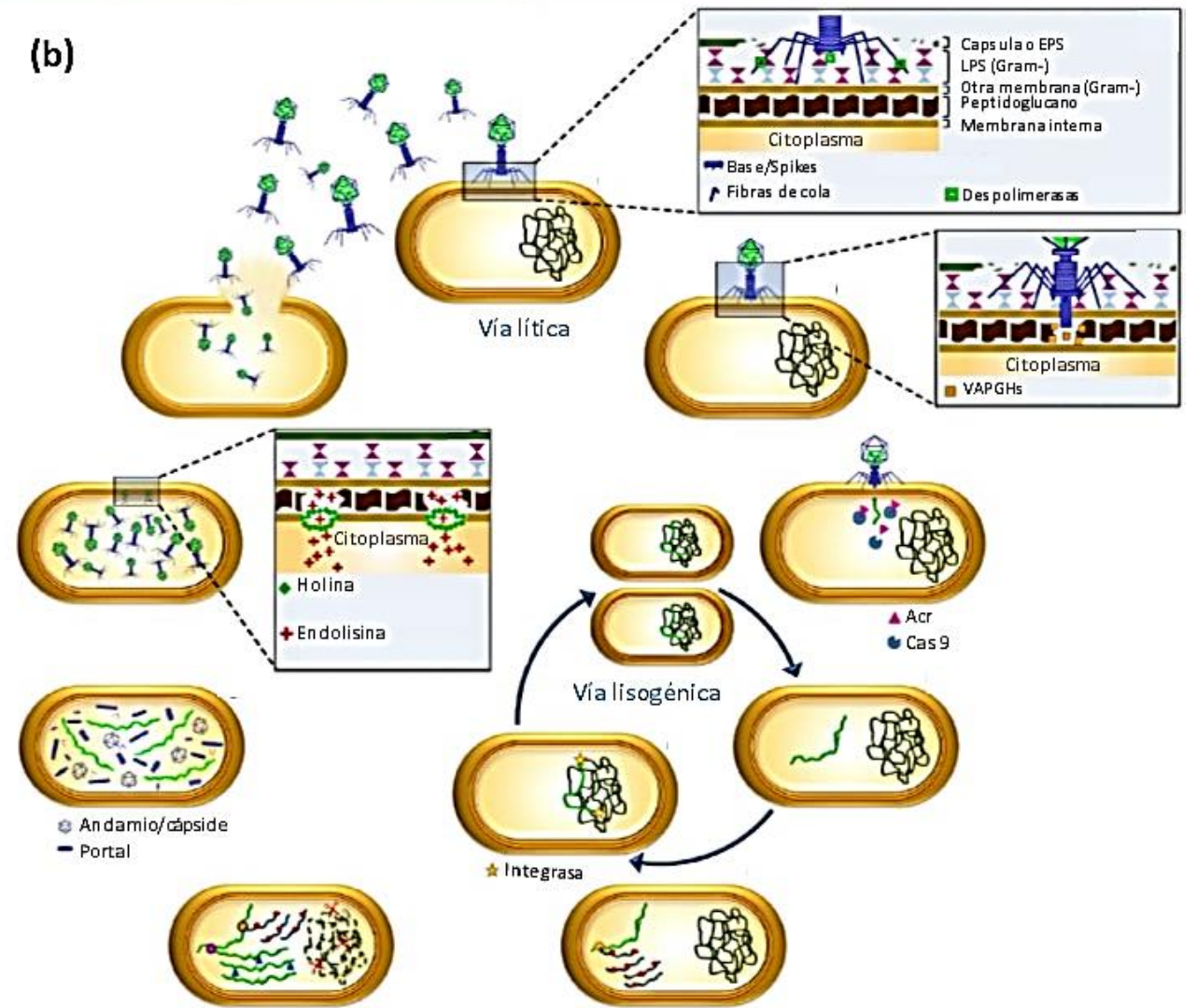

글 Integrasa

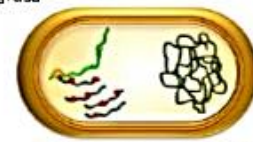

- ARN polimerasa h ospedado

- ARN polimerasafago

- ADN polimerasafago

$\triangle$ ADN ligasafago

- Ribosoma hospedador

) $A R N m$

$\times$ Nucl easasfago

Figura 2. a Estructura de bacterias y fagos, y símbolos que representan proteínas codificadas por fagos. b el ciclo de infección de los fagos. Adaptado de Santos et al. (2018).

La vía oral es la más práctica en crianza comercial, ya que permite realizar tratamientos en grandes cantidades de aves con menos tiempo y recursos, mediante el agua o alimento. Se ha demostrado que los fagos agregados tanto en el agua como en el alimento llegan a los distintos órganos internos afectados por las bacterias objetivo (Hong et al., 2013; Seo et al., 2018). Además, según los estudios realizados, los efectos de la fago-terapia depende de la concentración y cantidad de dosis y la duración del tratamiento. Por lo tal motivo, se justifica la utilización de los fagos líticos en crianza comercial ya que reducen de mortalidad incluso en aves desafiadas con dosis letales de bacterias patógenas.

\section{Fagos protegidos}

El pH 7 es el óptimo para estos virus, con una reducción de títulos de fagos a medida que disminuye el $\mathrm{pH}$, no resisten a medios muy ácidos $(\mathrm{pH}<3)$. Teniendo en cuenta que el pH gástrico de los pollos es aproximadamente 2,8 (Colom et al., 2015), es natural que muchos se pierdan en ese tramo del tracto digestivo y es necesario protegerlos (Colom et al., 2015; Kaikabo et al., 2016; Tie et al., 2018). 
Tabla 1

Efecto de la inclusión de fagos en aves desafiadas con bacterias patógenas

\begin{tabular}{|c|c|c|c|c|c|c|c|c|c|c|c|}
\hline Desafío & Dosis de bacteria & Fago & Familia de fago & Dosis fago & $\begin{array}{c}\text { Procedencia del } \\
\text { fago }\end{array}$ & Vía & $\begin{array}{l}\text { Nú- } \\
\text { mero de } \\
\text { dosis }\end{array}$ & $\begin{array}{l}\text { Duración del } \\
\text { tratamiento }\end{array}$ & Animal & Resultado & Referencias \\
\hline $\begin{array}{l}\text { C. perfringens } \\
+ \text { E. maxina } \\
\text { ( } 5000 \text { ooquistes) }\end{array}$ & $\begin{array}{c}1 \times 10^{8} \\
\text { UFC/animal }\end{array}$ & $\begin{array}{l}\text { CPAS-7 } \\
\text { CPAS-12 } \\
\text { CPAS-15 } \\
\text { CPAS-16 } \\
\text { CPTA-37 } \\
\text { CPLV-42 }\end{array}$ & Siphoviridae & $\begin{array}{c}2,5 \times 10^{9} \\
\text { UFP/animal/día }\end{array}$ & $\begin{array}{c}\text { Granjas avícolas y } \\
\text { plantas de } \\
\text { procesamiento }\end{array}$ & Agua & 5 & $\begin{array}{l}\text { Desde día } 3 \text { post } \\
\text { desafío hasta día } \\
7 \text { post desafío }\end{array}$ & $\begin{array}{l}\text { Pollos de } \\
42 \text { días }\end{array}$ & $\begin{array}{c}\text { Reducción de } \\
\text { mortalidad de } \\
66,67 \% \text { a } \\
18,00 \% \\
\text { Reducción de } \\
\text { mortalidad de } \\
66,67 \% \text { a 3,33\% } \\
\text { Reducción de } \\
\text { mortalidad de } \\
66,67 \% \text { a } 5,33 \% \\
\end{array}$ & $\begin{array}{l}\text { Miller et al. } \\
\text { (2010) }\end{array}$ \\
\hline $\begin{array}{l}\text { Salmonella } \\
\text { gallinarum }\end{array}$ & $\begin{array}{c}1 \times 10^{8} \\
\text { UFC/animal }\end{array}$ & $\begin{array}{l}\text { ST4 } \\
\text { L13 } \\
\text { SG3 }\end{array}$ & Siphoviridae & $\begin{array}{l}1 \times 10^{8} \\
\text { UFP/kg }\end{array}$ & $\begin{array}{l}\text { Aguas } \\
\text { residuales }\end{array}$ & Alimento & 28 & $\begin{array}{c}\text { Desde día } 7 \\
\text { antes del desafío } \\
\text { hasta día } 21 \text { post } \\
\text { desafío }\end{array}$ & $\begin{array}{l}\text { Pollos de } \\
42 \text { días }\end{array}$ & $\begin{array}{c}\text { Reducción de } \\
\text { mortalidad de } \\
40 \% \text { a } 25 \% \text {. }\end{array}$ & $\begin{array}{l}\text { Hong et al. } \\
\text { (2013) }\end{array}$ \\
\hline $\begin{array}{l}\text { Escherichia coli } \\
\mathrm{O} 1: \mathrm{K} 1 \mathrm{H} 7\end{array}$ & $\begin{array}{c}2 \times 10^{8} \\
\text { UFC/animal }\end{array}$ & KAZ14 & Myoviridae & $\begin{array}{c}2 \times 10^{6} \\
\text { UFP/animal }\end{array}$ & - & Oral $^{1}$ & 1 & Día de desafío & $\begin{array}{l}\text { Pollos de } \\
\text { un día }\end{array}$ & $\begin{array}{c}\text { Reducción de } \\
\text { mortalidad de } \\
58,33 \% \text { a } \\
16,70 \% \\
\end{array}$ & $\begin{array}{l}\text { Kaikabo et al. } \\
\text { (2016) }\end{array}$ \\
\hline $\begin{array}{l}\text { Salmonella } \\
\text { pullorum }\end{array}$ & $\begin{array}{c}5 \times 10^{7} \\
\text { UFC/animal }\end{array}$ & YSP2 & Siphoviridae & $\begin{array}{c}8 \times 10^{8} \\
\text { UFP/animal }\end{array}$ & $\begin{array}{l}\text { Aguas } \\
\text { residuales }\end{array}$ & Oral ${ }^{1}$ & 1 & Día de desafío & $\begin{array}{l}\text { Pollos de } \\
\text { un día }\end{array}$ & $\begin{array}{c}\text { Reducción de } \\
\text { mortalidad } 80 \text { a } \\
50 \%\end{array}$ & Tie et al. (2018) \\
\hline E. coli E28 & $\begin{array}{c}7,9 \times 10^{8} \\
\text { UFC/animal }\end{array}$ & $\begin{array}{c}\text { AB27 } \\
\text { TB49 } \\
\text { G28 } \\
\text { EW2 } \\
\end{array}$ & - & $\begin{array}{l}5 \times 10^{6} \\
\text { UFP/ml }\end{array}$ & Heces & Agua & 36 & 36 días & $\begin{array}{l}\text { Pollos de } \\
36 \text { días }\end{array}$ & $\begin{array}{l}\text { Reducción de } E \text {. } \\
\text { coli }\end{array}$ & $\begin{array}{l}\text { Kittler et al. } \\
\text { (2020) }\end{array}$ \\
\hline $\begin{array}{l}\text { Salmonella } \\
\text { enterica }\end{array}$ & $\begin{array}{c}5 \times 10^{4} \\
\text { UFC/animal }\end{array}$ & $\begin{array}{c}8 \text { sent1748 } \\
\text { 8sent65 3sent1 } \\
5 \text { sent1 }\end{array}$ & $\begin{array}{c}\text { Demerecviridae } \\
\text { Demerecviridae } \\
\text { Demerecviridae } \\
\text { Siphoviridae }\end{array}$ & $\begin{array}{c}2 \times 10^{6} \\
\text { UFP/animal/día }\end{array}$ & - & Alimento & 35 & 35 días & $\begin{array}{l}\text { Pollos de } \\
35 \text { días }\end{array}$ & $\begin{array}{c}\text { Reducción de } \\
\text { Salmonella en } \\
\text { ciego }\end{array}$ & $\begin{array}{l}\text { Wójcik et al. } \\
\text { (2020) }\end{array}$ \\
\hline $\begin{array}{l}\text { C. perfringens } \\
+ \text { coccidia } \\
\text { (20000 } \\
\text { ooquistes) }\end{array}$ & $\begin{array}{c}1 \times 10^{8} \\
\text { UFC/animal }\end{array}$ & $\varphi \mathrm{CJ} 22$ & Siphoviridae & $\begin{array}{l}1 \times 10^{7} \\
\text { UFP/kg }\end{array}$ & & Alimento & 35 & 35 días & $\begin{array}{l}\text { Pollos de } \\
35 \text { días }\end{array}$ & $\begin{array}{c}\text { Reducción de } \\
\text { mortalidad de } \\
17.95 \% \text { a } 8.33 \%\end{array}$ & Bae et al. (2021) \\
\hline
\end{tabular}


Tabla 2

Efecto de fagos protegidos sobre la población de bacterias patógenas como desafío (UFC/g)

\begin{tabular}{|c|c|c|c|c|c|c|c|c|c|c|}
\hline Desafío & $\begin{array}{l}\text { Dosis de } \\
\text { bacteria }\end{array}$ & Fago & $\begin{array}{c}\text { Dosis de } \\
\text { fago }\end{array}$ & C & NP & $P$ & DPI & Tratamiento & Protección & Autor \\
\hline $\begin{array}{l}\text { Escherichia coli } \\
01: \mathrm{K} 1: \mathrm{H} 7\end{array}$ & $\begin{array}{c}2 \times 10^{8} \text { UFC/ } \\
\text { Animal }\end{array}$ & KAZ14 & $\begin{array}{c}2 \times 10^{6} \\
\text { UFP/ } \\
\text { Animal } \\
\end{array}$ & $\begin{array}{c}2,31 \times 10^{8} \\
\pm 0,01^{a}\end{array}$ & $\begin{array}{l}1,95 \times 10^{4} \\
\pm 0,03^{b}\end{array}$ & $\begin{array}{l}1,09 \times 10^{2} \\
\pm 0,10^{b, c}\end{array}$ & $\begin{array}{c}21 \\
\text { días }\end{array}$ & $\begin{array}{l}\text { Día del } \\
\text { desafío }\end{array}$ & $\begin{array}{c}\text { Nanopartí- } \\
\text { culas de } \\
\text { quitosano }\end{array}$ & $\begin{array}{c}\text { Kaikabo et } \\
\text { al. (2016) }\end{array}$ \\
\hline $\begin{array}{l}\text { Salmonella } \\
\text { typhimurium }\end{array}$ & $\begin{array}{c}1 \times 10^{7} \text { UFC/ } \\
\text { Animal }\end{array}$ & $\begin{array}{l}\text { UAB_Phi20 } \\
\text { UAB_Phi78 } \\
\text { UAB_Ph87 }\end{array}$ & $\begin{array}{l}1 \times 10^{10} \\
\text { UFP/ } \\
\text { Animal }\end{array}$ & $\begin{array}{r}2,51 \times 10^{6} \\
\pm 1 \times 10\end{array}$ & $\begin{array}{c}5,01 \times 10^{5} \pm \\
7,9 \times 10\end{array}$ & $\begin{array}{l}3,16 \times 10^{2} \pm \\
6,3 \times 10^{2} b, c\end{array}$ & $\begin{array}{c}10 \\
\text { días }\end{array}$ & $\begin{array}{c}1 \text { día antes y } \\
8 \text { días post } \\
\text { desafío }\end{array}$ & Liposomas & $\begin{array}{l}\text { Colom et } \\
\text { al. (2015) }\end{array}$ \\
\hline
\end{tabular}

C: control, NP: no protegido, P: protegido, DPI: días post infección. ${ }^{\mathrm{a}-\mathrm{c}}$ Valores representan el promedio \pm SEM. Valores en una fila con diferente letra tienen diferencia significativa.

Además, se observó disminución de títulos de fagos a temperatura de $70^{\circ} \mathrm{C}$ durante 40 minutos o más y que no resisten temperaturas mayores o iguales a $80^{\circ} \mathrm{C}$ (Tie et al., 2018), por lo que el proceso de peletizado puede disminuir los títulos de fagos y es necesario protegerlos. Por tal motivo, se probó la encapsulación para proteger los fagos evidenciando menor mortalidad de las aves con fagos protegidos comparados con los no protegidos $16,7 \%$ y 50,0\% respectivamente (Kaikabo et al., 2016), mayor cantidad de fagos en el ciego de las aves a las 48 y 72 horas post tratamiento en fagos protegidos que en no protegidos existiendo diferencia estadística (Colom et al., 2015). Además, se observaron mejores resultados en la reducción de bacterias patógenas en fagos protegidos, esto debido a una menor pérdida de títulos de fagos al transitar por el sistema gastrointestinal que tiene cambios de $\mathrm{pH}$ y temperatura (Tabla 2), aunque dichos estudios se evaluaron a nivel de género bacteriano. Por lo tanto, la protección es una estrategia para disminuir la pérdida de títulos de fagos de los cocteles mixtos de fagos líticos y obtener mejores resultados.

\section{Fago-resistencia}

Dado que las bacterias y bacteriófagos co-evolucionaron desde la existencia de ambos, es lógico pensar que las presas (bacterias) han desarrollado estrategias para eludir a sus depredadores (fagos) y estos han desarrollado formas de superar dichas estrategias (Tabla 3). De hecho, existen reportes sobre la fago-resistencia bacteriana (Carvalho et al., 2010; Fischer et al., 2013; Colom et al., 2015; Sørensen et al., 2015; Richards et al., 2019) y se han estudiado los diversos mecanismos como: pérdida de fago-receptores, modificación de fago-receptores, sistema CRISPR-Cas y producción de matriz de polisacáridos (Brockhurst et al., 2017).

La modificación y pérdida de fago receptores sirven para evitar la adhesión del fago a la superficie bacteria, pero esto reduce la multiplicación bacteriana y los fagos pueden cambiar sus fibras de cola para encontrar los receptores recién alterados (Munsch-Alatossava \& Alatossava, 2013). En cuanto a la producción de polisacáridos, estos evitan la adhesión de los fagos, sin embargo, los fagos pueden producir despolimerasas para degradarlos (Wang et al., 2019). Finalmente, el sistema CRISPR-Cas forma parte del sistema inmune adaptativo de las bacterias y lo utilizan para degradar el material genético del fago, no obstante, algunos fagos pueden proteger su material genético con una cubierta proteica (Malone et al., 2020). Por otro lado, para combatir la fago-resistencia contamos con cocteles de fagos y quorum quenching (Hoque et al.,
2016; Quiroz-Guzmán et al., 2018; Mion et al., 2019a; Mion et al., 2019b; Richards et al., 2019); por lo tanto, se justifica que el empleo de fagos en avicultura comercial debe ser en cocteles o en combinación con quorum quenching.

\section{Empleo de cóctel de fagos en aves}

La mejor manera para emplear fagos en producción avícola comercial es mediante cocteles (Zhao et al., 2012; Wang et al., 2013; Kim et al., 2013; Kim et al., 2014; Ahmadi et al., 2016; Kim et al., 2017; Clavijo et al., 2019), ya que es difícil determinar todas las cepas bacterianas presentes en un centro de producción avícola y la presencia de bacterias fago-resistentes. Se han estudiado tanto fagos individuales como cocteles simples y mixtos. Donde, la diferencia entre fagos individuales y cocteles es la cantidad de fagos contra un mismo género bacteriano, donde a partir de dos fagos se considera como coctel, sin importar a que familia de fago pertenecen (Fischer et al., 2013). La diferencia entre cocteles simples y cocteles mixtos radica en la variedad de fagos contra géneros bacterianos, donde se considera como coctel mixto a partir de dos géneros bacterianos (Kim et al., 2014; Schulz et al., 2018). Si bien es cierto que los fagos tienen un espectro limitado, los cocteles mixtos son una estrategia para ampliar dicho espectro.

Los estudios realizados iniciaron con dosis bajas y fueron aumentando gradualmente, incluso, incrementaron los géneros y cepas bacterianas objetivo, formando cocteles y demostrando resultados superiores a los fagos individuales. Además, los estudios parecen indicar que los cocteles mixtos son más eficientes que los cocteles simples al controlar la población de bacterias potencialmente patógenas que forman parte de la microbiota intestinal, aunque tengan menor dosis de fagos (Tabla 4).

Sin embargo, aún faltan más estudios que evalúen el recuento bacteriano post tratamiento de la cepa bacteria objetivo, dado que la mayoría de los trabajos evalúan solamente los géneros bacterianos, microbiota intestinal y en menor medida la excreción, que se ha estudiado para controlar la transmisión horizontal.

Del mismo modo, los fagos han demostrado sinergismo al emplearse junto a los probióticos y ser más efectivos que estos al reducir las bacterias patógenas (Gebru et al., 2010; Kim et al., 2014; Kim et al., 2017). En tal sentido, se debería comparar con otras alternativas como prebióticos, aceites esenciales y ácidos orgánicos como se realizaron en otras especies animales y el efecto sobre el tamaño de vellosidades intestinales y profundidad de criptas. 
Tabla 3

Fago-resistencia y estrategias de solución

\begin{tabular}{|c|c|c|}
\hline Estrategia bacteriana & Función & Solución \\
\hline Modificación y perdida de fago-receptores & Evitar adhesión del fago & Modificación de fibras de cola del fago, coctel de fagos, quorum quenching. \\
\hline Producción de polisacáridos & Evitar adhesión del fago & Producción de despolimerasas, quorum quenching. \\
\hline Degradación del material genético del fago & $\begin{array}{l}\text { Evitar degradación del material genético } \\
\text { bacteriano }\end{array}$ & Coctel de fagos, quorum quenching. \\
\hline
\end{tabular}

\section{Tabla 4}

Efectos bacteriófagos sobre microbiota (log10 UFC/g) de aves

\begin{tabular}{|c|c|c|c|c|c|c|c|c|c|c|}
\hline & $\mathrm{C}^{1}$ & $\mathrm{~B}^{1}$ & $\mathrm{SEM}^{2}$ & Dosis de fago & Vía & $\begin{array}{c}\text { Tiempo de } \\
\text { estudio }\end{array}$ & Fago & Bacteria hospedera & Animal & Referencias \\
\hline $\begin{array}{l}\text { Heces } \\
\text { - Lactobacillus spp. } \\
\text { - E. coli } \\
\text { - Salmonella spp. }\end{array}$ & $\begin{array}{l}7,54 \\
6,59^{\mathrm{a}} \\
3,47^{\mathrm{a}}\end{array}$ & $\begin{array}{l}7,44 \\
6,23^{b} \\
2,11^{b}\end{array}$ & $\begin{array}{l}0,09 \\
0,11 \\
0,05\end{array}$ & $5 \times 10^{7} \mathrm{UFP} / \mathrm{kg}$ & Alimento & 42 días & Anti-Salmonella & $\begin{array}{l}\text { S. gallinarum } \\
\text { S. typhimurium } \\
\text { S. enteritidis }\end{array}$ & $\begin{array}{l}\text { Gallinas de postura } \\
\text { Hy-Line }\end{array}$ & Zhao et al. (2012) \\
\hline $\begin{array}{l}\text { Heces } \\
\text { - Lactobacillus spp. } \\
\text { - E. coli } \\
\text { - Salmonella spp. }\end{array}$ & $\begin{array}{l}6,38^{\mathrm{b}} \\
6,75^{\mathrm{a}} \\
3,24^{\mathrm{a}}\end{array}$ & $\begin{array}{l}6,72^{\mathrm{a}} \\
6,28^{\mathrm{b}} \\
2,64^{\mathrm{b}}\end{array}$ & $\begin{array}{l}0,11 \\
0,13 \\
0,16\end{array}$ & $5 \times 10^{7} \mathrm{UFP} / \mathrm{kg}$ & Alimento & 32 días & Anti-Salmonella & $\begin{array}{l}\text { S. gallinarum } \\
\text { S. typhimurium } \\
\text { S. enteritidis }\end{array}$ & Broilers Arbor Acres & Wang et al. (2013) \\
\hline $\begin{array}{l}\text { Ciego } \\
\text { - Lactobacillus spp. } \\
\text { - E. coli } \\
\text { - Salmonella enteritidis }\end{array}$ & $\begin{array}{l}6,25 \\
4,92 \\
6,31^{\mathrm{a}}\end{array}$ & $\begin{array}{r}6,27 \\
4,91 \\
4,23^{b}\end{array}$ & $\begin{array}{l}0,09 \\
0,22 \\
0,81\end{array}$ & $2 \times 10^{9} \mathrm{UFP} / \mathrm{kg}$ & Alimento & 35 días & Anti-Salmonella & S. Enteritidis & Broilers Ross 308 & Kim et al. (2013) \\
\hline $\begin{array}{l}\text { Ciego } \\
\text { - Lactobacillus spp. } \\
\text { - Bifidobacterium spp. } \\
\text { - Salmonella spp. } \\
\text { - E. coli } \\
\text { - C. perfringens }\end{array}$ & $\begin{array}{l}6,44 \\
6,10 \\
4,93 \\
6,12\end{array}$ & $\begin{array}{l}6,82 \\
6,00 \\
4,24 \\
6,32\end{array}$ & $\begin{array}{l}0,410 \\
0,250 \\
0,313 \\
0,455\end{array}$ & $5 \times 10^{7} \mathrm{UFP} / \mathrm{kg}$ & Alimento & 35 días & $\begin{array}{l}\text { Anti-Staphylococcus } \\
\text { Anti-Clostridium }\end{array}$ & $\begin{array}{l}\text { S. gallinarum } \\
\text { S. typhimurium } \\
\text { S. enteritidis } \\
\text { S. derby } \\
\text { S. aureus } \\
\text { C. perfringens A y C }\end{array}$ & Broilers Ross 308 & Kim et al. (2014) \\
\hline $\begin{array}{l}\text { Íleon } \\
\text { - Aerobios totales } \\
\text { - Lactobacillus spp. } \\
\text { - Colibacilos } \\
\text { - Streptococcus spp. }\end{array}$ & $\begin{array}{l}8,54 \\
6,31 \\
8,31 \\
5,74 \\
\end{array}$ & $\begin{array}{l}7,39 \\
7,78 \\
7,99 \\
6,79 \\
\end{array}$ & $\begin{array}{c}0,0001 \\
0,001 \\
0,01 \\
0,003 \\
\end{array}$ & $1 \times 10^{9} \mathrm{UFP} / \mathrm{mL}$ & Oral & 6 días & Anti-Salmonella & S. enteritidis & $\begin{array}{l}\text { Codornices } \\
\text { japonesas }\end{array}$ & Ahmadi et al. (2016) \\
\hline
\end{tabular}


Tabla 5

Efectos de cocteles de bacteriófagos sobre parámetros productivos de aves suministrados en el alimento

\begin{tabular}{|c|c|c|c|c|c|c|c|c|c|}
\hline Parámetros productivos ${ }^{1}$ & $C^{2}$ & $\mathrm{~B}^{2}$ & $\mathrm{SEM}^{3}$ & Dosis & Tiempo de estudio & Coctel de fago & Bacteria hospedera & Animal & Referencias \\
\hline GP (g/ave) & $2296^{C}$ & $2547^{b}$ & 0,059 & $2,5 \times 10^{9}$ UFP/ & 42 días & Anti-Clostridium & C. perfringens & Broilers Cobb & Miller et al. (2010) \\
\hline Conversión alimenticia & $3,226^{\mathrm{a}}$ & $2,089^{c}$ & 0,039 & animal/día & 42 uids & 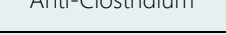 & c. perfiningens & 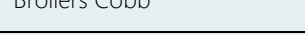 & TVImer El al. (CUTO) \\
\hline Producción de huevos (\%) semana 0-3 & $90,8^{b}$ & $91,8^{\mathrm{a}}$ & 0,22 & \multirow{3}{*}{$5 \times 10^{7} \mathrm{UFP} / \mathrm{kg}$} & \multirow{3}{*}{42 días } & \multirow[t]{3}{*}{ Anti-salmonella } & S. gallinarum & \multirow{3}{*}{ Gallinas de postura Hy-Line } & \multirow{3}{*}{ Zhao et al. (2012) } \\
\hline Producción de huevos (\%) semana 4-6 & $89,9^{b}$ & $91,6^{a}$ & 0,55 & & & & S. Typhimurium & & \\
\hline Peso de huevo $(\mathrm{g})$ semana 6 & 58,9 & 59,7 & 0,62 & & & & S. Enteritidis & & \\
\hline GP (g/ave) & 1410 & 1427 & 14 & \multirow{3}{*}{$5 \times 10^{7} \mathrm{UFP} / \mathrm{kg}$} & \multirow{3}{*}{32 días } & \multirow{3}{*}{ Anti-Salmonella } & S. gallinarum & \multirow{3}{*}{ Broilers Arbor Acres } & \multirow{3}{*}{ Wang et al. (2013) } \\
\hline CP (g/ave) & 2208 & 2181 & 23 & & & & S. typhimurium & & \\
\hline Conversión alimenticia & 1,566 & 1,528 & 0,017 & & & & S. enteritidis & & \\
\hline GP (g/ave) & 1947 & 1950 & 10,64 & \multirow{3}{*}{$2 \times 10^{9} \mathrm{UFP} / \mathrm{kg}$} & \multirow{3}{*}{35 días } & \multirow{3}{*}{ Anti-Salmonella } & \multirow{3}{*}{ S. Enteritidis } & \multirow{3}{*}{ Broilers Ross 308} & \multirow{3}{*}{ Kim et al. (2013) } \\
\hline CP (g/ave) & 3211 & 3211 & 21,69 & & & & & & \\
\hline Conversión alimenticia & 1,65 & 1,65 & 0,01 & & & & & & \\
\hline GP (g/ave) & $1770^{b}$ & $1847^{\mathrm{ab}}$ & 31,1 & \multirow{3}{*}{$\begin{array}{l}5 \times 10^{7} \mathrm{UFP} / \mathrm{kg} \\
5 \times 10^{7} \mathrm{UFP} / \mathrm{kg} \\
5 \times 10^{5} \mathrm{UFP} / \mathrm{kg}\end{array}$} & \multirow[b]{3}{*}{35 días } & \multirow{2}{*}{ Anti-Salmonella } & S. gallinarum & \multirow[b]{3}{*}{ Broilers Ross 308} & \multirow[b]{3}{*}{ Kim et al. (2014) } \\
\hline CP (g/ave) & 2851 & 2877 & 32,3 & & & & S. typhimurium & & \\
\hline Conversión alimenticia & $1,62^{\mathrm{a}}$ & $1,56^{b}$ & 0,018 & & & $\begin{array}{l}\text { Anti-Staphylococcus } \\
\text { Anti-Clostridium }\end{array}$ & $\begin{array}{l}\text { S. enteritidis } \\
\text { S. derby } \\
\text { S. aureus } \\
\text { C. perfringens A y C }\end{array}$ & & \\
\hline GP (g/ave) & 1712,19 & 1784,71 & 23 & $1 \times 10^{8} \mathrm{UFP} / \mathrm{kg}$ & 35 días & Anti-Salmonella & S. gallinarum & & \\
\hline CP (g/ave) & 2846,52 & 2887,22 & 30,64 & & & Anti-E. coli & $\begin{array}{l}\text { S. typhimurium } \\
\text { S. enteritidis } \\
\text { E. coli }\end{array}$ & Broilers Ross 308 & $\begin{array}{l}\text { Upadhaya et al. } \\
\text { (2021) }\end{array}$ \\
\hline Conversión alimenticia & 1,665 & 1,619 & 0,023 & $1 \times 10^{6} \mathrm{UFP} / \mathrm{kg}$ & & Anti-Clostridium & C. perfringens & & \\
\hline
\end{tabular}

Los tratamientos dietéticos fueron dieta basal sin ningún antimicrobiano (C) y dieta basal suplementada con cóctel de bacteriófago (B).

GP: ganancia de peso promedio, CP: consumo de alimento promedio. 2SEM: error estándar.

Tabla 6

Efectos de bacteriófagos y antibióticos sobre microbiota intestinal (log10 UFC/g)

\begin{tabular}{|c|c|c|c|c|c|c|c|c|c|}
\hline & C & A & $B$ & $\mathrm{SEM}^{1}$ & Dosis de coctel fago & Bacteria hospedera & Dosis de antibiótico & Animal & Autor \\
\hline \multicolumn{10}{|l|}{ Heces } \\
\hline E. coli & $6,75^{a}$ & $6,32^{b}$ & $6,28^{b}$ & 0,13 & \multirow{3}{*}{$5 \times 10^{7} \mathrm{UFP} / \mathrm{kg}$} & & \multirow{3}{*}{$\begin{array}{l}0,5 \mathrm{~g} / \mathrm{kg} \text { de Bacitracina } \\
\text { metileno disalicilato }\end{array}$} & \multirow{3}{*}{$\begin{array}{c}\text { Broilers Arbor Acres } \\
\text { de un día. }\end{array}$} & \multirow{3}{*}{ Wang et al. (2013) } \\
\hline Lactobacillus spp. & $6,38^{b}$ & $6,36^{b}$ & $6,72^{\mathrm{a}}$ & 0,11 & & Salmonella & & & \\
\hline Salmonella spp. & $3,24^{\mathrm{a}}$ & $2,56^{\mathrm{b}}$ & $2,64^{b}$ & 0,16 & & & & & \\
\hline \multicolumn{10}{|l|}{ Ciego } \\
\hline Lactobacillus spp. & 7,01 & 6,92 & 6,85 & 0,290 & \multirow{5}{*}{$\begin{array}{l}5 \times 10^{7} \mathrm{UFP} / \mathrm{kg} \\
5 \times 10^{7} \mathrm{UFP} / \mathrm{kg} \\
5 \times 10^{5} \mathrm{UFP} / \mathrm{kg}\end{array}$} & Salmonella & \multirow{5}{*}{$\begin{array}{c}0,025 \\
\mathrm{~g} / \mathrm{kg} \text { de Avilami-cina }\end{array}$} & \multirow{5}{*}{$\begin{array}{l}\text { Broilers Ross } 308 \\
\text { de un día. }\end{array}$} & \multirow{5}{*}{$\begin{array}{l}\text { Kim et al. } \\
\text { (2014) }\end{array}$} \\
\hline Bifidobacterium spp. & 6,17 & 5.74 & 5,87 & 0,177 & & S. aureus & & & \\
\hline Salmonella spp. & 4,87 & 4,62 & 4,24 & 0,222 & & Clostridium & & & \\
\hline E. coli & 6,87 & 6,51 & 6,52 & 0,322 & & & & & \\
\hline C. perfringens & $4,36^{a}$ & $3,97^{\mathrm{ab}}$ & $3,75^{b}$ & 0,141 & & & & & \\
\hline
\end{tabular}

C. perfringens

$5 \times 10^{7} \cup F P / k g$

S. aureus

0,14

/kg de Avilami-cina de un día. 


\section{Efecto de los fagos sobre los parámetros productivos}

Los cocteles de fagos han mostrado efectos positivos sobre los parámetros productivos en pollos de engorde y gallinas de postura comercial. Según los estudios realizados, los cocteles mixtos tienen mejores resultados sobre la conversión alimenticia que los cocteles simples, existiendo diferencia estadística, incluso cuando la dosis de cocteles simples es mayor; además, los bacteriófagos aumentaron la producción y peso de huevos en las primeras semanas de producción de gallinas de postura comercial mostrando diferencia estadística (Tabla 5). Según lo expuesto en los capítulos anteriores, se puede decir que fagos influyen indirectamente sobre los parámetros productivos al reducir las bacterias potencialmente patógenas y favorecen la multiplicación de las bacterias benéficas, lo que resulta en un mejor aprovechamiento de los nutrientes y que estos efectos pueden potenciar al usar fagos protegidos y en mayores dosis.

\section{Comparación entre fagos y promotores de crecimiento tipo antibióticos}

Los trabajos realizados en aves demostraron que los bacteriófagos son más eficaces que los antibióticos al disminuir sólo las bacterias patógenas (Wang et al., 2013; Kim et al., 2014); no obstante, se observó mejores resultados con cocteles mixtos de fagos, debiéndose no sólo a la reducción de la población de bacterias patógenas objetivo, sino también a la multiplicación de las bacterias benéficas (Tabla 6). Adicionalmente, los fagos son una buena alternativa contra bacterias resistentes a los antibióticos ya que los fagos utilizan mecanismos distintos a estos fármacos, sin embargo, falta realizar más estudios con mayores dosis de cocteles de fagos como los que utilizan actualmente y emplear fagos protegidos.

Una ventaja de los bacteriófagos frente a los antibióticos es que las bacterias resistentes a los antibióticos no pierden su capacidad de generar daño (virulencia), mientras que las bacterias resistentes a los fagos pueden ser menos virulentas (Laanto et al., 2012; Castillo et al., 2015; Castillo et al., 2018). Dado que, los receptores de la superficie celular de las bacterias patógenas actúan como factores de virulencia, por lo que, al modificarlos para desarrollar fago-resistencia reduce su virulencia. Sin embargo, la desventaja frente a los antibióticos sigue siendo el menor espectro de acción, por lo cual se propone el uso de cocteles mixtos de fagos líticos para aumentarlo. Los fagos pueden ser utilizados como promotores de crecimiento en los momentos críticos como el despique, vacunación (siempre que no se trate de vacunación contra bacterias) y traslado que afectan el consumo de alimento; y con ello evitar el aumento de bacterias potencialmente patógenas, que afectan negativamente los parámetros productivos.

\section{Autofagos}

En el mercado existen muchos productos comerciales (Tabla 7) cuyo principio activo son cocteles simples de fagos líticos. La mayoría de estos productos proceden de países europeos, asiáticos y norteamericanos, que tienen realidades y desafíos diferentes. Lo anterior, sumado a la cantidad de serovares (Pulido-Landínez, 2013; Guibourdenche et al, 2017; Moawad et al., 2018) presentes en los centros avícolas y la alta especificidad de los bacteriófagos, reduce la probabilidad de encontrar un producto comercial cuyo espectro incluya las bacterias presentes en un centro productivo determinado. En esta situación, existen tres posibilidades: que todas, algunas o ninguna de las bacterias presentes en una granja comercial formen parte del espectro del producto comercial. Por tal motivo, antes de adquirir un producto comercial, la empresa avícola debe asegurarse que las bacterias presentes en la granja sean susceptibles al producto comercial. Además, deben considerar que se trate de cocteles de fagos líticos protegidos y aún mejor si son cocteles contra múltiples géneros bacterianos (cocteles mixtos).

Por otro lado, el uso de autofagos es una alternativa de solución cuando un producto comercial no muestra los efectos deseados, donde se denomina autofago (AP) a un bacteriófago que fue aislado del mismo entorno donde se encontró el patógeno (Sevilla-Navarro et al, 2018). Lo cual implicaría la implementación adecuada de los laboratorios de las granjas para el aislamiento y amplificación de dichos autofagos y considerar las recomendaciones expuestas en este artículo. Incluso, las granjas avícolas pueden ampliar este concepto y buscar fagos en aguas residuales de diferentes centros avícolas.

Tabla 7

Productos comerciales de fagos para aves

\begin{tabular}{|c|c|c|c|c|}
\hline Bacteria objetivo & Nombre del producto & Nombre de la empresa & Número de fagos & Referencias \\
\hline Salmonella & SalmoFREE ${ }^{\circledR}$ & Sciphage (Colombia) & 6 & Clavijo et al. (2019) \\
\hline Salmonella & Bafasal ${ }^{\circledR}$ & $\begin{array}{c}\text { Proteon Pharmaceuticals } \\
\text { (Polonia) }\end{array}$ & 4 & $\begin{array}{l}\text { Wójcik et al. (2020), } \\
\text { Proteonpharma (2020) }\end{array}$ \\
\hline C. perfringens & INT-401 ${ }^{\mathrm{TM}}$ & $\begin{array}{c}\text { Intralytix Inc. (Estados } \\
\text { Unidos) }\end{array}$ & 5 & $\begin{array}{l}\text { Colom et al. (2015), Intralytix } \\
\text { Inc. (2020) }\end{array}$ \\
\hline $\begin{array}{l}\text { E. coli } \\
\text { Salmonella } \\
\text { C. perfringens }\end{array}$ & Biotector ${ }^{\circledR}$ & $\begin{array}{l}\text { CJ CheilJedang Research } \\
\text { Institute of } \\
\text { Biotechnology (Corea del } \\
\text { Sur) }\end{array}$ & N.E & CJBIO (2020) \\
\hline $\begin{array}{l}\text { E. coli } \\
\text { Salmonella } \\
\text { C. perfringens } \\
\text { Streptococcus } \\
\text { Staphylococcus }\end{array}$ & Phagovet ${ }^{\circledR}$ & RPC Micromir (Rusia) & N.E & Micromir (2020) \\
\hline
\end{tabular}




\section{Conclusiones}

En el presente trabajo se ha descrito a los bacteriófagos líticos como excelentes sustitutos de antibióticos como promotores de crecimiento en avicultura. Dado que, estudios experimentales demostraron su capacidad para reducir la mortalidad en aves desafiadas con bacterias patógenas y mejorar los parámetros productivos. Así mismo, se ha justificado la necesidad de protegerlos, la utilización de cocteles de fagos líticos para combatir la fago-resistencia y el uso de cocteles mixtos para aumentar el espectro. Por lo tanto, la utilización óptima en avicultura comercial es mediante cocteles mixtos de fagos líticos protegidos. Finalmente, existen productos comerciales, sin embargo, es necesario que se elaboren cocteles mixtos de fagos líticos protegidos y que sean personalizados según los desafíos de cada granja; por lo cual, los autofagos son una alternativa cuando los productos comerciales no muestran los efectos deseados.

\section{Agradecimientos}

Agradecimiento a la V Convocatoria de Proyectos de Ciencia y Tecnología en la Universidad Nacional de Trujillo con Recursos Públicos provenientes del CANON (2021) por el financiamiento brindado.

\section{ORCID}

C. E. Honorio-Javes (D) https://orcid.org/0000-0002-8917-7085

Y. Vallenas-Sánchez (D) https://orcid.org/0000-0003-1262-5959

J. T. Bazán Pérez (D) https://orcid.org/0000-0003-1152-4080

\section{Referencias bibliográficas}

Ackerman, H. (2011). Bacteriophage taxonomy. Microbiol Aust. 32(2), 90-94.

Ahmadi, M., Torshizi, M. A., Rahimi, S., \& Dennehy, J. J. (2016). Prophylactic Bacteriophage Administration More Effective than Post-infection Administration in Reducing Salmonella enterica serovar Enteritidis Shedding in Quail. Frontiers in Microbiology, 7, 1253-1262.

Amato, H. K., Wong, N. M., Pelc, C., Taylor, K., Price, L. B., et al. (2020). Effects of concentrated poultry operations and cropland manure application on antibiotic resistant Escherichia coli and nutrient pollution in Chesapeake Bay watersheds. Science of The Total Environment, 735, 139401.

Assafi, M. S., Hado, H. A., \& Abdulrahman, I. S. (2020). Detection of methicillin-resistant Staphylococcus aureus in broiler and broilers farm workers in Duhok, Iraq by using conventional and PCR techniques. Iraqi J Vet Sci, 34(1), 15-22.

Bae, D., Lee, J.-W., Chae, J.-P., Kim, J.-W., Eun, J.-S., et al. (2021). Characterization of a novel bacteriophage $\varphi \mathrm{CJ} 22$ and its prophylactic and inhibitory effects on necrotic enteritis and Clostridium perfringens in broilers. Poultry Science, 100(1), 302-313.

Brockhurst, M. A., Koskella, B., \& Zhang, Q.-G. (2017). BacteriaPhage Antagonistic Coevolution and the Implications for Phage Therapy. In: Bacteriophages Ed. por D. Harper, S., Abedon, B., Burrowes, M. McConville. Springer International Publishing. Pp. 1-21.

Carvalho, C. M., Gannon, B. W., Halfhide, D. E., Santos, S. B., Hayes, C. M., et al. (2010). The in vivo efficacy of two administration routes of a phage cocktail to reduce numbers of Campylobacter coli and Campylobacter jejuni in chickens. BMC Microbiology, 10(1), 232-343.

Castillo, D., Christiansen, R. H., Dalsgaard, I., Madsen, L., \& Middelboe, M. (2015). Bacteriophage resistance mechanisms in the fish pathogen Flavobacterium psychrophilum: Linking genomic mutations to changes in bacterial virulence factors. Applied and Environmental Microbiology, 81(3), 1157-1167.

Castillo, D., Rørbo, N., Jørgensen, J., Lange, J., Tan, D., et al. (2019). Phage defense mechanisms and their genomic and phenotypic implications in the fish pathogen Vibrio anguillarum. FEMS Microbiology Ecology, 95(3), 1-13.

CJBIO - CheilJedang Research Institute of Biotechnology. (2020). Biotector ${ }^{\circledR}$. Disponible en: https://www.cjbio.net/en/products/biotector.do

Clavijo, V., Baquero, D., Hernandez, S., Farfan, J. C., Arias, J., et al. (2019). Phage cocktail SalmoFREE ${ }^{\circledR}$ reduces Salmonella on a commercial broiler farm. Poultry Science, 98(10), 5054-5063.

Colom, J., Cano-Sarabia, M., Otero, J., Cortés, P., Maspoch, D., \& Llagostera, M. (2015). Liposome-encapsulated bacteriophages for enhanced oral phage therapy against Salmonella spp. Appl Environ Microbiol, 81(14), 4841- 4849.

Colomer-Lluch, M., Jofre, J., \& Muniesa, M. (2011). Antibiotic resistance genes in the bacteriophage DNA fraction of environmental samples. PLoS One, 6(3), -e17549.

ESVAC. (2017). Sales of veterinary antimicrobial agents in 30 european countries in 2015. Trends from 2010 to 2015. Available https://www.ema.europa.eu/en/documents/report/seventhesvac-report-sales-veterinary-antimicrobial-agents-30european-countries-2015_en.pdf

Fischer, S., Kittler, S., Klein, G., \& Glünder, G. (2013). Impact of a Single Phage and a Phage Cocktail Application in Broilers on Reduction of Campylobacter jejuni and Development of Resistance. PLOS ONE, 8(10), e78543.

Gebru, E., Lee, J. S., Son, J. C., Yang, S.Y., Shin, S. A., et al. (2010). Effect of probiotic-, bacteriophage-, or organic acidsupplemented feeds or fermented soybean meal on the growth performance, acute-phase response, and bacterial shedding of grower pigs challenged with Salmonella enterica serotype Typhimurium. Journal of Animal Science, 88(12), 3880-3886.

Guibourdenche, M., Roggentin, P., Mikoleit, M., Fields, P. I., Bockemühl, J., et al. (2010). Supplement 2003-2007 (No. 47) to the White-Kauffmann-Le Minor scheme. Research in Microbiology, 167(1), 26-29.

Hong, S., Jeong, J., Lee, J., Kim, S., Min, W., \& Myung, H. (2013). Therapeutic Effects of Bacteriophages Against Salmonella gallinarum Infection in Chickens. J. Microbiol. Biotechnol, 23(10), 1478-1483.

Hoque, M. M., Naser, I. B., Bari, S. M. N., Zhu, J., Mekalanos, J. J., \& Faruque S. M. (2016). Quorum Regulated Resistance of Vibrio cholerae against Environmental Bacteriophages. Scientific Reports, 6(1), 37956.

Hubbard, L. E., Givens, C. E., Griffin, D. W., Iwanowicz, L. R., Meyer, M. T., \& Kolpin, D. W. (2020). Poultry litter as potential source of pathogens and other contaminants in groundwater and surface water proximal to large-scale confined poultry feeding operations. Science of The Total Environment. 735, 139459.

Intralytix Inc. (2020). INT-401' ${ }^{\text {TM }}$ Disponible en: http://www.intralytix.com/index.php?page=vet

Kaikabo, A., AbdulKarim, S., \& Abas, F. (2016). Evaluation of the efficacy of chitosan nanoparticles loaded DKAZ14 bacteriophage in the biological control of colibacillosis in chickens. Poultry Science, 96(2), 295-302.

Kim, J. H., Kim, J. W., Lee, B. B., Lee, G. I., Lee, J. H., et al. (2014). Effect of dietary supplementation of bacteriophage on growth performance and cecal bacterial populations in broiler chickens raised in different housing systems. Livestock Science, 170, 137-141.

Kim, J. S., Hosseindoust, A., Lee, S. H., Choi, Y. H., Kim, M. J., et al. (2017). Bacteriophage cocktail and multi-strain probiotics in the feed for weanling pigs: effects on intestine morphology and targeted intestinal coliforms and Clostridium. Animal, 77(01), 45-53. 
Kim, K. H., Lee, G. Y., Jang, J. C., Kim J., \& Kim, Y. (2013). Evaluation of Anti-SE Bacteriophage as Feed Additives to Prevent Salmonella Enteritidis (SE) in Broiler. Asian-Aust. J. Anim. Sci, 26(3), 386-393.

Kittler, S., Mengden, R., Korf, I. H. E., Bierbrodt, A., Wittmann, J., et al. (2020). Impact of Bacteriophage-Supplemented Drinking Water on the E. coli Population in the Chicken Gut. Pathogens, 9(4), 293.

Laanto, E., Bamford, J. K. H., Laakso, J., \& Sundberg, L.-R. (2012). Phage-Driven Loss of Virulence in a Fish Pathogenic Bacterium. PLOS ONE, 7(12), e53157.

Malone, L. M., Warring, S. L., Jackson, S. A., Warnecke, C., Gardner, P. P., et al. (2020). A jumbo phage that forms a nucleus-like structure evades CRISPR-Cas DNA targeting but is vulnerable to type III RNA-based immunity. Nature Microbiology, 5, 4855.

Mazhar, S. H., Li, X., Rashid, A., Su, J., Xu, J., et al. (2020). CoSelection of Antibiotic Resistance Genes, and Mobile Genetic Elements in the presence of Heavy Metals in Poultry Farm Environments. Science of The Total Environment, 2, 142702.

Micromir - RPC Micromir. (2020). Phagovet ${ }^{\circledR}$. Disponible en: https://micromir.bio/phagovet

Miller, R. W., Skinner, J., Sulakvelidze, A., Mathis, G. F., \& Hofacre, C. L. (2010). Bacteriophage Therapy for Control of Necrotic Enteritis of Broiler Chickens Experimentally Infected with Clostridium perfringens. Avian Diseases, 54(1), 33-40.

Mion, S., Plener, L., Rémy, B., Daudé, D., \& Chabrière, É. (2019a). Lactonase SsoPox modulates CRISPR-Cas expression in gram-negative proteobacteria using $\mathrm{AHL}$-based quorum sensing systems. Research in Microbiology, 170(6), 296-299.

Mion, S., Rémy, B., Plener, L., Brégeon, F., Chabrière, E., \& Daudé, D. (2019b). Quorum Quenching Lactonase Strengthens Bacteriophage and Antibiotic Arsenal Against Pseudomonas aeruginosa Clinical Isolates. Front. Microbiol, 10, 2049.

Moawad, A. A., Hotzel, H., Awad, O., Tomaso, H., Neubauer, H., et al. (2017). Occurrence of Salmonella enterica and Escherichia coli in raw chicken and beef meat in northern Egypt and dissemination of their antibiotic resistance markers. Gut Pathogens, 9(57), 1-13.

Munsch-Alatossava, P., \& Alatossava, T. (2013). The extracellular phage-host interactions involved in the bacteriophage $\mathrm{LL}-\mathrm{H}$ infection of Lactobacillus delbrueckii ssp. lactis ATCC 15808. Front Microbiol, 4, 408.

Ngamwongsatit, B., Tanomsridachchai, W., Suthienkul, O., Urairong, S., Navasakuljinda, W., \& Janvilisri, T. (2016). Multidrug resistance in Clostridium perfringens isolated from diarrheal neonatal piglets in Thailand. Anaerobe, 38, 88-93.

Parry-Hanson, K. A., Otwey, R. Y., \& Mosi, L. (2020). Microbiological quality and Salmonella prevalence, serovar distribution and antimicrobial resistance associated with informal raw chicken processing in Accra, Ghana. Food Control, 118, 107440.

Proteonpharma - Proteon Pharmaceuticals. (2020). Bafasal ${ }^{\circledR}$. Disponible https://www.proteonpharma.com/products/bafasal-poultry/

Pulido-Landínez, M., Washington, P., Thornton, J. K., Zhang, Y., Sánchez-Ingunza, R., et al. (2013). Serotype and Antimicrobial Resistance Patterns of Salmonella Isolates from Commercial Birds and Poultry Environment in Mississippi. Avian Diseases, 58(1), 64-70.

Quiroz-Guzmán, E., Peña-Rodriguez, A., Vázquez-Juárez, R., Barajas-Sandoval, D. R., Balcázar, J. L., \& Martínez-Díaz, S. F. (2018). Bacteriophage cocktails as an environmentally-friendly approach to prevent Vibrio parahaemolyticus and Vibrio harveyi infections in brine shrimp (Artemia franciscana) production. Aquaculture, 492, 273-279.

Richards, P. J., Connerton, P. L., \& Connerton, I. F. (2019). Phage Biocontrol of Campylobacter jejuni in Chickens Does Not
Produce Collateral Effects on the Gut Microbiota. Front. Microbiol, 10, 476-486.

Santos, S., Costa, A., Carvalho, C., Nóbrega, F., \& Azeredo, J. (2018). Exploiting Bacteriophage Proteomes: The Hidden Biotechnological Potential. Trends in Biotechnology, 36(9), 966-984.

Schulz, P., Robak, S., Dastych, J., \& Siwicki, A. K. (2018). Influence of bacteriophages cocktail on European eel (Anguilla anguilla) immunity and survival after experimental challenge. Fish Shellfish Immun. 84, 28-37.

Seo, B.-J., Song, E.-T., Lee, K., Kim, J.-W., Jeong, C.-G., et al. (2018). Evaluation of the broad-spectrum lytic capability of bacteriophage cocktails against various Salmonella serovars and their effects on weaned pigs infected with Salmonella Typhimurium. Journal of Veterinary Medical Science, 80(6), 851-860.

Sevilla-Navarro, S., Marín, C., Cortés, V., García, C., Vega, S., \& Catalá-Gregori, P. (2018). Autophage as a control measure for Salmonella in laying hens. Poultry Science, 97(12), 4367-4373.

Sørensen, M. C. H., Gencay, Y. E., Birk, T., Baldvinsson, S., Jäckel, C., \& Hammerl, J. (2015). Primary Isolation Strain Determines Both Phage Type and Receptors Recognised by Campylobacter jejuni Bacteriophages. PLOS ONE, 10(1), e0116287.

Tie, K., Yuan, Y., Yan, S., Yu, X., Zhang, Q., et al. (2018). Isolation and identification of Salmonella pullorum bacteriophage YSP2 and its use as a therapy for chicken diarrhea. Virus Genes, 54(3), 446-456.

Upadhaya, S. D., Ahn, J. M., Cho, J. H., Kim, J. Y., Kang, D. K., et al. (2021). Bacteriophage cocktail supplementation improves growth performance, gut microbiome and production traits in broiler chickens. Journal of Animal Science and Biotechnology, 12(1), 49.

Wang, C., Li, P., Niu, W., Yuan, X., Liu, H., Huang, Y., et al. (2019). Protective and therapeutic application of the depolymerase derived from a novel KN1 genotype of Klebsiella pneumoniae bacteriophage in mice. Research in Microbiology, 170(3), $156-$ 164.

Wang, J. P., Yan, L., Lee, J. H., \& Kim, I.H. (2013). Evaluation of Bacteriophage Supplementation on Growth Performance, Blood Characteristics, Relative Organ Weight, Breast Muscle Characteristics and Excreta Microbial Shedding in Broilers. Asian-Australas J Anim Sci, 26(4), 573-578.

Weinbauer, M. (2004). Ecology of prokaryotic viruses. FEMS Microbiol Rev, 28(2), 127-181.

Welsh, J. E., Steenhuis, P., de Moraes, K. R., van der Meer, J., Thieltges, D. W., \& Brussaard, C. P. D. (2020). Marine virus predation by non-host organisms. Scientific Reports, 10, 5221.

Wipf, J., Schwendener, S., \& Perreten, V. (2014). The novel macrolide-lincosamide-streptogramin $B$ resistance gene erm (44) Is associated with a prophage in Staphylococcus xylosus. Antimicrob. Agents Chemother, 58, 6133-6138.

Wójcik, E. A., Stańczyk, M., Wojtasik, A., Kowalska, J. D., Nowakowska, M., Łukasiak, M., et al. (2020). Comprehensive Evaluation of the Safety and Efficacy of BAFASAL ${ }^{\circledR}$ Bacteriophage Preparation for the Reduction of Salmonella in the Food Chain. Viruses, 12(7): 742-769.

Zhao, P. Y., Baek, H. Y., \& Kim, I. H. (2012). Effects of Bacteriophage Supplementation on Egg Performance, Egg Quality, Excreta Microflora, and Moisture Content in Laying Hens. AsianAustralasian Journal of Animal Sciences, 25(7), 1015-1020.

Zwe, Y., Tang, V., Aung, K., Gutiérrez, R., Ng, L., \& Yuk, H-G. (2018). Prevalence, sequence types, antibiotic resistance and, gyrA mutations of Salmonella isolated from retail fresh chicken meat in Singapore. Food Control, 90, 233-240. 